\title{
Energy Metabolism in Children with Newly Diagnosed Acute Lymphoblastic Leukemia
}

\author{
VIRGINIA A. STALLINGS, ${ }^{1}$ NACHUM VAISMAN, HELEN S. L. CHAN, SHEILA S. WEITZMAN, \\ ELIZABETH HAHN, AND PAUL B. PENCHARZ \\ Divisions of Clinical Nutrition and Haematology/Oncology and the Research Institute, The Hospital for Sick \\ Children, and the Departments of Paediatrics and Nutritional Sciences, University of Toronto, \\ Toronto, Ontario, Canada
}

\begin{abstract}
The effect of tumor burden in acute Iymphoblastic leukemia on resting energy expenditure, thermic effect of food, and substrate utilization was investigated with open-circuit indirect calorimetry after an overnight fast. Nine patients (six females, three males) ages 6.5 to $15.8 \mathrm{y}$ were studied. Patients were divided into two groups according to their tumor burden at diagnosis (i.e. white cell count, presence or absence of mediastinal mass, or massive organomegaly). The patients with a greater tumor burden had increased energy expenditure. Their resting energy expenditure returned to normal in response to chemotherapy. These results must be interpreted with caution due to the small patient numbers (high tumor burden $n=3$; low tumor burden $n=6$ ). Substrate utilization was altered by chemotherapy with an increase in carbohydrate utilization and a decrease in fat oxidation $(p<0.009)$. The magnitude of the thermic effect of food tended to increase on treatment $(p<0.016)$. Inasmuch as most chemotherapy programs for children last up to $3 \mathrm{y}$, we believe it is important that the effects of chemotherapy on intermediary metabolism be studied, particularly in relationship to any possible permanent effects on growth and development. (Pediatr Res 26: 154-157, 1989)
\end{abstract}

\section{Abbreviations}

ALL, acute lymphoblastic leukemia

REE, resting energy expenditure

TEF, thermic effect of food

WBC, white blood cell

Malignant diseases are commonly associated with significant wt loss or "cancer cachexia" (1-3). Wt loss may be mild with early disease but is generally severe with advanced malignancy. $\mathrm{Wt}$ loss has been attributed to many different factors, such as anorexia, poor intake, malabsorption and hypermetabolism due to the large tumor load or to associated fever and infection. One previous publication addressed the question of energy expenditure in children with newly diagnosed ALL (4). The authors measured energy expenditure once during the first weeks after diagnosis. They did not distinguish between chemotherapy

Received January 7, 1988; accepted April 14, 1989

Correspondence and reprint requests to Paul Pencharz, M.B., Ch.B., Ph.D. Division of Clinical Nutrition, The Hospital for Sick Children, 555 University Ave., Toronto, Ontario, Canada, M5G 1 X8.

Supported in part by a grant from the National Cancer Institute of Canada V.A.S. was supported by a Fellowship from The Hospital for Sick Children, and N.V. by a Fellowship from the Canadian Cystic Fibrosis Foundation.

'Present address The Children's Hospital of Philadelphia, 34th and Civic Center Blvd., Philadelphia, PA 19104. treated and untreated patients, or those with a low and a high white blood count. Only one component of energy expenditure, the REE, was measured. They showed that the REE was significantly increased in ALL patients, compared to controls.

Inasmuch as it is unclear whether the increased energy expenditure reported in newly diagnosed children with ALL is due to differences in tumor burden, substrate utilization, or TEF, we designed our study to examine these parameters separately. We also studied the effect of chemotherapy on the patients' tumor burden and energy utilization during the first $2 \mathrm{wk}$ of treatment.

\section{PATIENTS AND METHODS}

Patients. Nine children with newly diagnosed ALL presenting to the Oncology Service at The Hospital for Sick Children in Toronto, between January 1984 and February 1986, were studied. The clinical findings at diagnosis, anthropometric measurement, and hematologic data are shown in Table 1. It proved difficult to recruit patients with a higher tumor burden, because they tend to be clinically unstable. We used WBC count and blast count as indicators of tumor burden (Table 1). The patients are divided into 2 groups according to their WBC: Group 1more than $50 \times 10^{9} /$ liter $(n=3)$, and/or massive mediastinal mass and hepatosplenomegaly. Group 2 -less than $50 \times 10^{9} /$ liter $(n=6)$.

All children in the study were clinically stable. The decision to allow a child to be studied was made by the responsible hematologist. The study was approved by the hospital's Human Subject Review Committee, in conformity with the Declaration of Helsinki. Informed consent was obtained from all the parents and when possible, also from the child. The patients were treated on two chemotherapy protocols, according to their risk factors. High-risk factors included: age older than $10 \mathrm{y}$, WBC more than $50 \times 10^{9}$ /liter, "lymphoma syndrome" (mediastinal mass, massive hepatosplenomegaly), unfavorably morphology $\left(\mathrm{L}_{2}\right.$, undifferentiated) $(5,6)$. Children with high-risk factors received intensive chemotherapy, whereas those without these findings (standard-risk) were treated with a less intensive program (7). During the first $2 \mathrm{wk}$ of induction (i.e. when energy metabolism was being studied), the high-risk patients' chemotherapy consisted of daily oral prednisone $\left(60 \mathrm{mg} / \mathrm{m}^{2} /\right.$ day $)$, intramuscular L-asparaginase $\left(6000 \mathrm{U} / \mathrm{m}^{2} /\right.$ dose $)$ three times a week, weekly intravenous vincristine $\left(1.5 \mathrm{mg} / \mathrm{m}^{2} /\right.$ dose $)$, and weekly intravenous daunomycin $\left(25 \mathrm{mg} / \mathrm{m}^{2} /\right.$ dose $)$. The patients who were treated with the standard-risk program received the same drugs, with the exception of daunomycin, during the first 2 wk of induction (5).

Experimental Procedure. The REE and the TEF were studied before the start of treatment (day 0), and then on day 7 and 14 of chemotherapy. Energy expenditure was studied by an opencircuit indirect calorimetry as previously described (8). REE was measured for $1 \mathrm{~h}$ after an overnight fast of 12 to $14 \mathrm{~h}$. The hood 
Table 1. Patient characteristics on admission

\begin{tabular}{|c|c|c|c|c|c|c|c|c|c|c|c|}
\hline Patient & Sex & Age $(y)$ & $\begin{array}{l}\text { Fever } \\
\left({ }^{\circ} \mathrm{C}\right)\end{array}$ & Wt $(\mathrm{kg})$ & $\begin{array}{l}\text { Height } \\
\text { (ht) } \\
(\mathrm{cm})\end{array}$ & $\mathrm{Wt} / \mathrm{ht} \%$ & $\begin{array}{c}\mathrm{Hb} \\
(\mathrm{g} / \mathrm{liter})\end{array}$ & $\begin{array}{l}\text { Platelet } \\
\left(\times 10^{9} /\right. \\
\text { liter })\end{array}$ & $\mathrm{WBC}$ & Blast & $\begin{array}{c}\text { Morphology } \\
\text { of blasts }\end{array}$ \\
\hline \multicolumn{12}{|c|}{ Group 1 (high tumor burden) } \\
\hline $1^{*}$ & $\mathrm{~F}$ & 14.1 & No & 63.5 & 172 & 88.2 & 71 & 15 & 84.3 & 79.24 & $\mathrm{~L} 1$ \\
\hline $2^{*}$ & M & 15.8 & No & 60.2 & 167 & 111.5 & 159 & 126 & 106.0 & 72.8 & $\mathrm{~L} 1, \mathrm{~T}$ cell \\
\hline $3^{*}$ & $\mathrm{~F}$ & 10.0 & No & 32.5 & 134 & 112.1 & 52 & 82 & 456.2 & 437.9 & $\mathrm{~L} 2, \mathrm{~T}$ cell \\
\hline Mean \pm & & $13.3 \pm$ & & & & $103.9 \pm$ & $77 \pm 79$ & $74.3 \pm 55.8$ & $215.5 \pm$ & $196.4 \pm$ & \\
\hline $\mathrm{SD}$ & & 2.9 & & & & 13.6 & & & 208.7 & 209.2 & \\
\hline \multicolumn{12}{|c|}{ Group 2 (low tumor burden) } \\
\hline $4^{*}$ & $\mathrm{~F}$ & 12.8 & 39.6 & 48.3 & 150 & 118.0 & 98 & 18 & 0.8 & 0 & L1 \\
\hline $5^{*}$ & M & 15.1 & 38.0 & 51.9 & 148 & 76.3 & 68 & 72 & 2.3 & 1.29 & L2 \\
\hline $6 \dagger$ & $\mathrm{F}$ & 9.0 & No & 27.2 & 136 & 82.4 & 62 & 114 & 3.6 & 1.06 & $\mathrm{Ll}$ \\
\hline $7^{*}$ & $\mathrm{~F}$ & 11.5 & No & 33.0 & 145 & 89.2 & 70 & 154 & 5.5 & 0.88 & $\begin{array}{l}\text { Undif- } \\
\text { feren- } \\
\text { tiated }\end{array}$ \\
\hline $8 \dagger$ & M & 6.5 & 39.2 & 21.3 & 123 & 88.8 & 92 & 283 & 6.7 & 2.75 & L1 \\
\hline $9^{*}$ & $\mathrm{~F}$ & 14.2 & No & 48.8 & 165 & 84.1 & 73 & 79 & 14.4 & 9.7 & $\mathrm{~L} 2$ \\
\hline Mean \pm & & $11.5 \pm$ & & & & $89.8 \pm$ & $77 \pm 14$ & $120 \pm$ & $5.55 \pm$ & $2.61 \pm$ & \\
\hline SD & & 3.2 & & & & 14.6 & & 91.8 & 4.82 & 3.58 & \\
\hline
\end{tabular}

* High risk chemotherapy program.

$\dagger$ Standard risk chemotherapy program.

of the calorimeter was removed and the patient was given a test meal of Carnation Instant Breakfast (Carnation Inc. Markham, Ontario, Canada) mixed with homogenized whole milk. This liquid test meal contained $1230 \mathrm{kcal} /$ liter. The protein, carbohydrate, and fat content of the test meal contributed 22,49 , and $29 \%$, respectively, of the caloric intake. The test meal provided a caloric intake of approximately $20 \%$ of the daily energy requirements of a healthy child of the same age and sex (9). Actual test meal energy intakes ranged from $185-565 \mathrm{kcal} / \mathrm{meal}$ (mean $424 \pm 134$ ). After the test meal, the hood of the calorimeter was replaced, and testing was continued for another $2 \mathrm{~h}$. A spot urine was collected for determination of urinary nitrogen excretion during the $1-h$ fasting REE study and a second urine during the 2-h TEF study.

Data analysis. Energy expenditure was calculated from the respiratory gas exchange using standard equations (10). The TEF was defined as the total increase in energy expenditure above the baseline REE, over the 2-h postprandial study. TEF was expressed both as a percentage of the REE and of the energy content of the test meal (Table 3).

The nonprotein respiratory quotient and protein oxidation was calculated from measurements of urinary nitrogen excretion. Fat and carbohydrate utilization were calculated from the nonprotein respiratory quotient $(11,12)$. A respiratory quotient of more than 1 is seen with lipogenesis from glucose. There is negative utilization (or synthesis) of fat and overutilization of glucose exceeding $100 \%$ after refeeding.

Both REE and TEF were compared to the standard predicted values for age, sex, and size reported by the World Health Organization (9). The percent predicted REE and TEF are considered to be the more accurate values for comparison purposes in a group of patients of different age, sex, and size. We have previously reported that these values obtained in healthy children using our indirect calorimetry system are in the normal range (8).

One of our original hypotheses was that tumor burden would affect energy metabolism. Despite extending the recruitment of subjects to over $2 \mathrm{y}$, we experienced great difficulty in enrolling patients with a high tumor burden, simply because on the whole they were too unstable clinically. Nonetheless, when we analyzed the data we were able to demonstrate, even with the small numbers (high tumor burden $n=3$; low tumor burden $n=6$ ), a highly significant effect of tumor burden on resting energy ex- penditure. With chemotherapy this difference tended to disappear. We also examined the effects of tumor burden on the thermic effect of feeding. Inasmuch as no differences were seen we decided to combine the two groups for the analysis of the effects of treatment on TEF.

The data are presented as mean \pm SD. Repeated measures analysis of variance and contrasts with Bonferroni corrections were used to compare the changes in energy metabolism with treatment.

The unpaired Student's $t$ test was used to compare the WBC counts and the energy expenditure in the two groups of patients, upon admission.

\section{RESULTS}

The age of the nine children (six females, three males) studied was $12.1 \pm 3.1 \mathrm{y}$, with a range from 6.5 to $15.8 \mathrm{y}$ (Table 1). The three children in group 1 had WBC counts of more than $50 \times$ $10^{9} /$ liter; two of the three (patients 2 and 3 ) also had associated lymphoma syndrome. All three were treated with the high-risk chemotherapy program (7). Although the WBC counts of the six children in group 2 were less than $50 \times 10^{9} /$ liter, four (patients $4,5,7$, and 9) were treated with the high-risk chemotherapy program because of their older age or unfavorable cell morphology. The other two (patients 6 and 8 ) were treated with a standard-risk chemotherapy program.

Three children in group 2 but none in Group 1 had fever at diagnosis. None of the children had recurrent fevers or infections during the 2-wk study period.

Only one child had a history of severe anorexia and had a wt loss of $9 \mathrm{~kg}$ at diagnosis (patient 9). The other eight children did not report significant anorexia and wt loss. All but two patients had wt for height ratios which were within the normal range. Chemotherapy had a variable effect on appetite and food intake during the 1st wk, but all patients were eating well by the 2 nd wk. The mean wt loss \pm SD (from admission) was $0.14 \pm 0.94$ $\mathrm{kg}$ in the $1 \mathrm{st} w \mathrm{k}$ and $0.93 \pm 1.57 \mathrm{~kg}$ by the end of the $2 \mathrm{nd} \mathrm{wk}$. The actual wt at study are shown in Table 2.

Before treatment (day 0), the REE in the nine patients ranged between $91.6-145.5 \%$ predicted (Table 2). The patients in group 1 had both significantly different total REE $(p<0.02)$ and percent predicted REE $(p<0.004)$ from those in group 2 . These differences did not show statistical correlation with the presence 
Table 2. REE before and during first 2 wk of treatment

\begin{tabular}{|c|c|c|c|c|c|c|c|c|c|}
\hline \multirow[b]{2}{*}{ Patient } & \multicolumn{3}{|c|}{ Day 0} & \multicolumn{3}{|c|}{ Day 7} & \multicolumn{3}{|c|}{ Day 14} \\
\hline & $\begin{array}{r}\text { Wt } \\
(\mathrm{kg})\end{array}$ & $\begin{array}{l}\text { Total REE } \\
\text { (kcal/day) }\end{array}$ & $\begin{array}{c}\text { REE } \\
\% \text { Predicted }\end{array}$ & $\begin{array}{l}\mathrm{Wt} \\
(\mathrm{kg})\end{array}$ & $\begin{array}{l}\text { Total REE } \\
\text { (kcal/day) }\end{array}$ & $\begin{array}{c}\text { REE } \\
\% \text { Predicted }\end{array}$ & $\begin{array}{l}\mathrm{Wt} \\
(\mathrm{kg})\end{array}$ & $\begin{array}{l}\text { Total REE } \\
\text { (kcal/day) }\end{array}$ & $\begin{array}{c}\text { REE } \\
\% \text { Predicted }\end{array}$ \\
\hline \multirow[t]{3}{*}{ Group 1} & 32.5 & 1674 & 145 & 32.7 & 1354 & 117 & 29.3 & 1320 & 114 \\
\hline & 60.2 & 1879 & 113 & 60.4 & 1376 & 82 & $\mathrm{~N} / \mathrm{D}$ & $N / D$ & N/D \\
\hline & 63.5 & 2301 & 135 & 63.2 & 1964 & 115 & 62.0 & 2052 & 120 \\
\hline Mean & 52.1 & $1951^{*}$ & $131^{*}$ & 52.1 & 1565 & 105 & 45.7 & 1686 & 117 \\
\hline \multirow[t]{6}{*}{ Group 2} & 33.0 & 1087 & 96 & 33.3 & 1159 & 103 & 33.0 & 1168 & 103 \\
\hline & 51.9 & 1748 & 109 & 51.9 & 1679 & 105 & 50.0 & 1820 & 113 \\
\hline & 27.2 & 996 & 91 & 27.2 & 915 & 84 & 27.2 & 914 & 84 \\
\hline & 48.3 & 1263 & 92 & 46.1 & 1077 & 79 & 46.0 & 1288 & 94 \\
\hline & 48.8 & 1297 & 94 & 49.5 & 977 & 71 & 49.5 & 1144 & 83 \\
\hline & 21.3 & 941 & 95 & N/D & N/D & $\mathrm{N} / \mathrm{D}$ & 22.0 & 658 & 66 \\
\hline Mean & 38.4 & $1222^{*}$ & $96^{*}$ & 41.6 & 1161 & 88 & 38.0 & 1165 & 91 \\
\hline
\end{tabular}

* Predicted REE are derived from Reference $9 . \%$ Pred $=$ Total REE/predicted $\times 100$. The total REE and REE percent of predicted are significantly different by group $(p<0.0001)$ and by treatment day $(p<0.001)$ by 2 -way analysis of variance. Post hoc analysis shows that the group 1 day 0 values are significantly increased ( $p<0.017$; Bon Ferroni correction). N/D, no data; study was not performed for technical reasons.

or absence of fever or wt loss. The REE difference appeared to be directly related to the tumor burden at diagnosis, as measured by the WBC and blast counts in the two groups $(p<0.01)$.

The differences in both total and percent predicted REE in the two groups of patients seen on day 0 were no longer apparent by day 7 and 14 of treatment. Concurrently, the mean WBC count $\pm \mathrm{SD}$ in patients in group 1 and 2 decreased to $3.06 \pm 2.2$ and $1.76 \pm 1.1 \times 10^{9} /$ liter, respectively, by day 7 of chemotherapy. By day 14 , mean WBC were $2.9 \pm 3.98$ and $1.43 \pm 0.95 \times 10^{9} /$ liter, respectively.

In the whole study population, the respiratory quotient increased significantly during the 1 st and $2 \mathrm{nd}$ wk of treatment ( $p$ $<0.0058$ ), but no difference was found between the two groups of patients. This increase in respiratory quotient was due to increased utilization of carbohydrate and to a concomitant decreased utilization of fat during the 2 -wk study period $(p<$ 0.009 ). No significant difference was found in the fasting protein oxidation during treatment, and there was no significant difference in the two groups of patients on days 0,7 , and 14 of treatment. These changes in substrate utilization after overnight fast are shown in Figure 1. The differences in carbohydrate and fat utilization at diagnosis in patients in group 1 and 2 approached significance $(p<0.07)$. These differences disappeared during the 2 wk of treatment.

The thermic effect of food increased significantly $(p<0.016)$ during the 2 nd wk of treatment, compared to pretreatment values (Table 3). The thermic effect of food expressed as a percentage of REE was significantly increased $(p<0.026)$ during treatment. When TEF was expressed as a percentage of the caloric content of the test meal, this difference was not apparent (Table 3).

\section{DISCUSSION}

Only a few studies have dealt with the question of energy expenditure in patients with cancer (13-15) and leukemia (4, 16). In a recent study by Kein and Camitta (4), the basal metabolic rate was found to be increased by $50 \pm 34 \%$ of predicted in children (ages 3-14 y) with ALL. REE or basal metabolic rate in their studies was measured using an open circuit system, comparable to our own, but measurements were continued for only $5 \mathrm{~min}$ compared with $60 \mathrm{~min}$ in our study. Kein and Camitta (4) do not provide any information regarding WBC or the timing of REE measurements with relationship to chemotherapy. REE was not correlated with the WBC or with chemotherapy. However, we found that only patients with a high

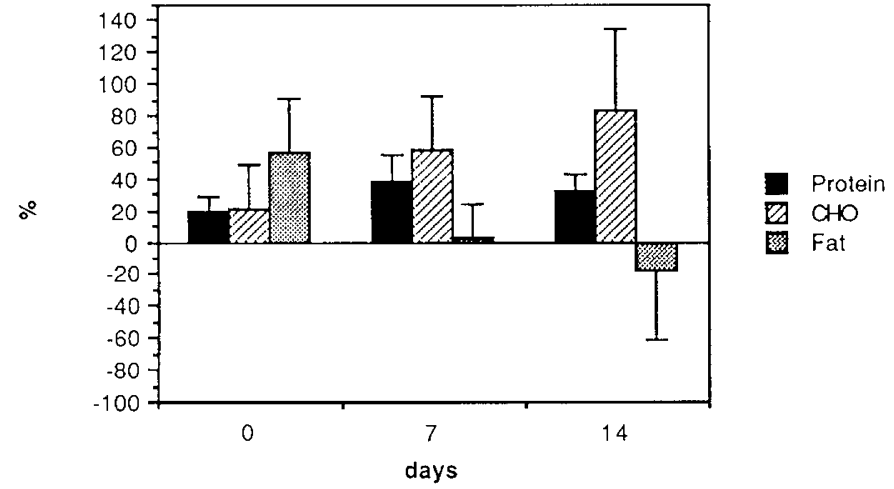

Fig. 1. The effects of chemotherapy on the contribution of protein, carbohydrate $(\mathrm{CHO})$ and fat to energy expenditure in children with ALL after an overnight fast. Carbohydrate utilization increases significantly ( $p$ $<0.009)$ whereas fat utilization falls $(p<0.009)$.

Table 3. TEF (2-h postmeal) before and during the first 2 wk of treatment (mean $\pm S D$ )

\begin{tabular}{lcccc}
\hline & \multicolumn{5}{c}{ TEF } \\
& $n$ & $(\mathrm{cal} / \mathrm{kg} / 2 \mathrm{~h})$ & TEF/REE $(\%)$ & TEF/intake (\%) \\
\hline Day 0 & $(9)$ & $282 \pm 230$ & $9.56 \pm 7.07$ & $3.55 \pm 2.47$ \\
Day 7 & $(8)$ & $323 \pm 127$ & $13.54 \pm 6.83$ & $3.74 \pm 2.13$ \\
Day 14 & $(8)$ & $556 \pm 160$ & $21.50 \pm 8.80$ & $6.38 \pm 3.63$ \\
$p$ value & & 0.016 & 0.026 & 0.096 \\
\hline
\end{tabular}

WBC count and "lymphoma syndrome" had a higher than normal REE. This increased energy expenditure was presumably due to the large tumor burden and the high cell turnover. The REE decreased back to the normal range when the tumor burden disappeared by day 7 and 14 of chemotherapy.

Changes in REE were also found by Knox et al. (13) in adult cancer patients. Both hypermetabolism and hypometabolism, as well as normal energy expenditure were observed. Their conclusion was that it was the duration of the illness rather than the type of malignancy that affected energy metabolism. Fearon et al. (17) were unable to demonstrate any increase in REE in adults with lung or colon cancer. Bozzetti et al. (15) attributed the excessive caloric expenditure as the cause of malnutrition in patients with cancer. 
The changes in the type of energy substrate utilization after overnight fast have not been previously reported in patients with cancer or leukemia. Protein oxidation did not change significantly in response to chemotherapy. However, carbohydrate utilization increased whereas fat utilization fell (Fig. 1). By day 14 fat utilization was actually negative which implies net fat synthesis and deposition (18). The question arises whether these changes are due to the reduction in tumor burden, in response to chemotherapy, or are due to direct effects of the chemotherapy. We cannot completely rule out the possible effects of changes in tumor burden, expecially in light of the effects of tumor mass on REE. However, in group 2 tumor mass does not appear to have any major effects on REE. Further, we were not able to show any significant differences in substrate utilization between the two groups on admission or in response to chemotherapy. We therefore believe it is more likely that the changes in substrate utilization were due to effects of the drugs on the patients' metabolism. Four drugs were used. Daunomycin inhibits DNA synthesis but has no known effect on intermediary metabolism (16). Vincristine interferes with protein and nucleic acid metabolism by preventing spindly formation during mitotic divisions (16). L-Asparaginase also interferes with protein metabolism (16). Corticosteroids affect metabolism by increasing gluconeogenesis and hepatic glycogen deposition (19). They also interfere with protein metabolism and are anabolic in the liver and catabolic in skeletal muscles as well as increasing lipolysis. The multiple effects of glucocorticosteroids on intermediary metabolism might explain the switch from fat utilization to increased carbohydrate utilization after an overnight fast. In the fasted state, we are aware of only one other situation where carbohydrate utilization increases, and net fat synthesis occurs, namely in the first few weeks of refeeding adolescent girls with anorexia nervosa (20). Our tentative explanation of this observation is that lipolysis must be suppressed and that substrate is derived from the carbon skeletons of amino acids. We, unfortunately, do not have any plasma substrate or hormone measurements. However, consistent with our interpretations, in the anorectic patient, urine nitrogen increased concomitantly with the increased carbohydrate utilization. In our study protein oxidation (calculated from urinary nitrogen excretion) increased numerically but did not reach statistical significance.

Waterhouse et al. (21) investigated a group of adult patients with different types of cancer. They found significantly increased conversion of alanine to glucose and impaired glucose tolerance (22). Their results support our finding of a change in the substrate utilization induced by chemotherapy. Costa et al. (23) also showed that tumors caused more than $80 \%$ suppression of $\mathrm{CO}_{2}$ formation from exogenous fats, and resulted in disturbed fat oxidation. Our findings of increased carbohydrate and reduced fat utilization after a test meal appeared to be related to chemotherapy. Chemotherapy also increased the thermic effect of food, above and beyond the $8-20 \%$ increase above REE seen in healthy children fed with $20 \%$ of their daily energy requirement in the form of a test meal (Vaisman N, Pencharz P, unpublished data). Our findings were based on calorimetric studies done for $2 \mathrm{~h}$ after a test meal. Inasmuch as the thermic effect of feeding had been reported to last for up to $6 \mathrm{~h}$ (24); our results should be interpreted with some caution. We had considered $6 \mathrm{~h}$ of calorimetry after the test meal, but this is an impractical study design for children with newly diagnosed ALL.

We conclude that the increased energy expenditure seen in some children with newly diagnosed ALL is due to the presence of greater tumor burden (25). The REE rapidly returned to normal with treatment and may be related to the decrease in WBC because lymphoblasts are generally very chemosensitive.
The chemotherapy-induced changes in substrate utilization appeared to be more persistent. Inasmuch as most chemotherapy programs for children with ALL last up to $3 \mathrm{y}$, longitudinal follow-up of intermediary metabolism is important to determine whether there is a profound and permanent effect on metabolism, growth, and development.

Acknowledgments. The authors are indebted to Mrs. Ruth Clarke for her help with sample analysis; to Mrs. Joyce Bernstein with the statistical analyses; and to the Research Institute Word Processing Centre for help with preparation of the manuscript.

\section{REFERENCES}

1. Theologides A 1979 Cancer cachexia. Cancer 43:2004-2012

2. Lawson DH, Richmond A, Nixon DW and Rudman D 1982 Metabolic approaches to cancer cachexia. Ann Rev Nutr 2:277-301

3. DeWys D 1982 Pathophysiology of cancer cachexia: Current understanding and areas for future research. Cancer Res 42 (suppl) 721-726

4. Kein CL, Camitta BM 1987 Close association of accelerated rates of whole body protein turnover (synthesis and breakdown) and energy expenditure in children with newly diagnosed acute lymphocytic leukemia. JPEN 11:129134

5. Mauer AM 1980 Therapy of acute lymphoblastic leukemia in childhood. Blood $56: 1-10$

6. Bennett JM, Catovsky D, Daniel MT, Flandrin G, Galton DAG, Gralnick HR, Sultan C 1981 The morphological classification of acute lymphoblastic leukaemia: concordance among observers and clinical correlations. $\mathrm{Br} \mathrm{J}$ Haematol 47:553-561

7. Hansjörg R, Helmut G, Günter H, Hans-Joachim L, Edelgard O 1980 The Berlin Childhood Acute Lymphoblastic Leukemia Therapy Study, 19701976. Am J Pediat Hematol/Oncol 4:299-306

8. Vaisman N, Pencharz PB, Corey M, Canny GH, Hahn E 1987 Energy expenditure of patients with cystic fibrosis. J Pediatr 111:496-500

9. WHO 1985 Energy and Protein Requirements. Report of a joint FAO/WHO/ UNO expert consultation. Technical Report Services no. 724. World Health Organization, Geneva

10. Lister G, Hoffman JIE, Rudolph AM 1974 Oxygen uptake in infants and children: A simple method for measurement. Pediatrics 53:656-662

11. Elwyn DH, Kinney JM 1980 A unique approach to measuring total energy expenditure by indirect calorimetry. In: Assessment of Energy Metabolism in Health and Disease. First Ross Conference. Ross Laboratories, Columbus, $\mathrm{OH}, \mathrm{pp} 54-62$

12. Frayn KN 1983 Calculation of substrate oxidation rates in vivo from gaseous exchange. J Appl Physiol 55:628-634

13. Knox LS, Crosby LO, Feumer JD, Buzby GP, Miller CL, Mullen JL 1983 Energy expenditure in malnourished cancer patients. Ann Surg 200:152162

14. Warnold I, Lundholm K, Schersten T 1978 Energy balance and body composition in cancer patients. Cancer Res 38:1801-1807

15. Bozzetti F, Pagnoni AM, Del Vecchio M 1980 Excessive caloric expenditure as a cause of malnutrition in patients with cancer. Surg Gynecol Obstetr 150:229-234

16. Attman AJ, Schwartz AD (eds) 1983 Cancer chemotherapy. In: Malignant Diseases of Infancy, Childhood and Adolescence. WB Saunders, Philadelphia, pp 59-95

17. Fearon KCH, Hansell DT, Preston T, Plumb JA, Davies J, Shapiro D, Shenkin A, Calman KC, Burns HJG 1988 Influence of whole body protein turnover rate on resting energy expenditure in patients with cancer. Cancer Res 48:2590-2595

18. Elia M, Livesey G 1988 Theory and validity of indirect calorimetry during net lipid synthesis. Am J Clin Nutr 47:591-607

19. Eistein AB, Singh SP 1980 Hormonal control of nutrient metabolism. In: Goodhart RS, Shils ME (eds) Modern Nutrition in Health and Disease, 6th ed. Lee \& Febiger, Philadelphia, pp 536-559

20. Vaisman N, Rossi M, Goldberg E, Hahn E, Clarke R, Pencharz PB 1987 "Abnormal" substrate utilization on refeeding patients with anorexia nervosa. Pediatr Res 21:643.

21. Waterhouse C, Jeanpretre N, Keilson J 1979 Gluconeogenesis from alanine in patients with progressive malignant disease. Cancer Res 39:1968-1972

22. Waterhouse C 1974 How tumors affect host metabolism. Acad Sci 230:86-93

23. Costa G, Lyles K, Ullrich L 1976 Effects of human and experimental cancer on the conversion of ${ }^{14} \mathrm{C}$ tripalmitin to ${ }^{14} \mathrm{CO}_{2}$. Cancer $38: 1259-1265$

24. Jequier E, Schutz Y 1985 New evidence for a thermogenic defect in human obesity. Int J Obesity (suppl 2):1-7

25. Günter H, Hans-Joachim L, Ursula K, Rolf L, Günther S, Brigitte S, Hansjörg R 1981 Thymic involvement and initial white blood count in childhood acute lymphoblastic leukemia. Am J Pediatr Hematol Oncol 4:369-376 